\title{
The Application Of Self-Employment Tax To Limited Liability Companies: A Critical Analysis
}

Timothy R. Koski, (E-mail: tkoski@mtsu.edu), Middle Tennessee State University

\begin{abstract}
One of the significant issues that has arisen in connection with limited liability companies (LLCS) electing to be taxed as a partnership is the application of self-employment tax to its members. The issue of when an LLC member's distributive share of LLC income is subject to self-employment tax has not been definitively answered. This paper reviews the current rules on when an LLC member's distributive share of LLC income is subject to self-employment tax and analyzes proposals that have been made to clarify the law in this area.
\end{abstract}

\section{INTRODUCTION}

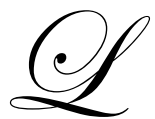

imited liability companies (LLCs) provide their members with limited liability similar to that available to corporate shareholders. In addition, LLCs can elect to be taxed as partnerships for federal income tax purposes and avoid the double tax problem of $\mathrm{C}$ corporations. Because of this "best of both worlds" treatment, LLCs have become an important form of business organization. One of the significant issues facing LLCs electing to be taxed as partnerships involves self-employment (SE) tax. The issue of when an LLC member's share of LLC income is subject to SE tax has not been definitively answered. This paper reviews the current rules on when an LLC member's share of LLC income is subject to SE tax and analyzes proposals that have been made to clarify the law in this area.

\section{BACKGROUND}

An individual is subject to SE tax on their net earnings from self-employment (NEFSE). In 2006 a tax of $12.4 \%$ is imposed on the first $\$ 94,200$ of NEFSE for old age, survivors, and disability insurance (Internal Revenue Code $\$ 1401(a)$ ). An additional tax of $2.9 \%$ is imposed on the entire amount of NEFSE for hospital insurance (Internal Revenue Code $\S 1401(b))$. The amount of NEFSE subject to the $12.4 \%$ tax is adjusted for inflation annually.

Internal Revenue Code Sec. 1402(a) provides that an individual's NEFSE includes the distributive share (whether or not distributed) of income or loss from any trade or business carried on by a partnership of which the individual is a member. Code Sec. 1402(a)(13) goes on to exclude the distributive share of a limited partner (other than guaranteed payments made for services actually rendered to the partnership) from NEFSE. Because limited partners are not active in the management of a partnership's trade or business, their share of income is properly considered a return on capital, rather than NEFSE. Although the theory behind excluding a limited partner's share of partnership income from SE tax is sound, the distinction between a general and limited partner is sometimes difficult to apply, especially for LLCs.

Prior to 1977 both general and limited partners were subject to SE tax on their distributive share of partnership income. Congress became concerned with investors becoming limited partners in business organizations in order to become insured under the social security system. Individuals, especially those close to retirement age, were becoming limited partners in partnerships that operated a trade or business primarily to obtain social security coverage. Because a limited partner's participation in the social security system was inconsistent with the basic principle of social security - to partially replace lost earnings from work - Congress amended Code Sec. 1402(a) in 
1977 to exclude a limited partner's share of partnership income (other than for guaranteed payments received for services actually rendered) from NEFSE (Social Security Amendments of 1977).

Times have changed since 1977. Because of increases in the SE tax rate, individuals now try to avoid SE tax, rather than pay SE tax to qualify for social security benefits. In addition, the distinction between general and limited partners is not as clear today as it was in 1977. Most state limited partnership acts now allow limited partners to take a more active role in the management of the business. It can be argued that the share of partnership earnings of limited partners who participate in management should be subject to SE tax. Applying the SE tax rules to LLC members is even more problematic. Although members of an LLC electing to be taxed as a partnership are partners for tax purposes, the terms general and limited partner are not used. The owners of LLCs are classified as "members." Unlike limited partners in traditional limited partnerships, LLC members often participate in the LLC's business and have limited liability. As discussed below, the Treasury Department (Treasury) twice issued proposed regulations setting forth criteria for differentiating LLC members whose share of partnership earnings are subject to SE tax (general partners) from those members whose share of earnings are not (limited partners).

\section{PROPOSED REGULATIONS}

In 1994 the Treasury issued proposed regulations applying Code Sec. 1402(a)(13) to LLCs. An LLC member was treated as a limited partner for purposes of Code Sec. 1402(a)(13) if (1) the individual lacked the authority to make management decisions for the LLC, and (2) the LLC could have been formed as a limited partnership rather than an LLC in the jurisdiction in which it was formed, and the member could have qualified as a limited partner in that limited partnership (Prop. Reg. §1.1402(a)-18(c)(3)).

Commentators criticized several aspects of the 1994 proposed regulations. State laws differ on the extent to which limited partners are allowed to participate in the partnership's business. Commentators expressed concern that basing the definition of limited partner on state law would lead to disparate treatment between members of different LLCs with identical rights based solely on the state in which the LLC is formed. A non-manager member of an LLC who participates in the LLC's business could be treated as a limited partner in an LLC formed in one state, but a general partner in an LLC formed in another.

Other commentators suggested a material participation test. They argued that basing the general versus limited partner distinction on the level of participation in the LLC's business would eliminate uncertainty surrounding many LLC members and better implement the goal of including only compensation for services in NEFSE.

Under the 1994 proposed regulations a partner was either a general partner or a limited partner with respect to his entire interest in the partnership. Commentators advocated adopting a rule that would make it clear that ownership of more than one type of interest in an LLC is allowed for SE tax purposes. They argued that Congress only intended to subject the distributive share of general partnership interests to SE tax, not the distributive share of limited partnership interests, even for individuals owning both types of interest in the same partnership.

The IRS withdrew the 1994 proposed regulations in 1997 and simultaneously issued new proposed regulations (Prop. Reg. § 1.1402(a)-2). Although the 1997 proposed regulations have never been finalized, they remain the only definitive guidance on applying Code Sec. 1402(a)(13) to LLCs, and are reviewed in detail below.

\section{PROPOSED REGULATIONS}

The 1997 proposed regulations specifically define a limited partner for purposes of Code Sec. 1402(a)(13). They apply to all entities classified as partnerships for federal income tax purposes regardless of state law classification of the entity, not just LLCs. As suggested by commentators, they treat similarly situated individuals owning interests in entities created under different statutes or in different jurisdictions the same. 
An individual is treated as a limited partner under the 1997 proposed regulations unless the individual -

(1) has personal liability for the debts of or claims against the partnership;

(2) has authority to contract on behalf of the partnership (under the laws of the jurisdiction in which the partnership is formed); or

(3) participates in the partnerships' trade or business for more than 500 hours during the year (Prop. Reg. $1.1402(\mathrm{a})-2(\mathrm{~h})(2)$.

The 1997 proposed regulations make it clear that guaranteed payments made to an individual for services rendered to or on behalf of a partnership are NEFSE, regardless of whether the individual is classified as a general or limited partner (Prop. Reg. 1.1402(a)-2(g)).

The 1997 proposed regulations allow for bifurcation of interests in the case of an individual holding more than one class of interest in a partnership, allowing a partner to be treated as both a general partner and a limited partner in the same partnership. This bifurcation rule excludes from NEFSE amounts that are "demonstrably returns on capital invested in the partnership" (Preamble to Prop. Reg. 1.1402(a)-2). An individual holding more than one class of interest in a partnership who is not treated as a limited partner with respect to one class of interest may nevertheless be treated as a limited partner with respect to another class of interest if, immediately after the individual acquires such interest, (1) limited partners own a substantial, continuing interest in that specific class of interest, and (2) the individual's rights and obligations with respect to that specific class of interest are identical to those of the other limited partners (Prop. Reg. 1.1402(a)-2(h)(3)). Whether an individual's interest in a specific class of partnership interest is continuing and substantial is based on all relevant facts and circumstances. Ownership of $20 \%$ or more of a specific class of interest is automatically considered substantial (Prop. Reg. 1.1402(a)-2(h)(6)(iv)). No guidance is provided as to when a partnership interest is continuing.

The 1997 proposed regulations also contain an exception for holders of only one class of interest. An individual who is not treated as a limited partner under the general rule of Prop. Reg. 1.1402-2(h)(2) solely because he or she participates in the partnership's trade or business for more than 500 hours during the year is nevertheless treated as a limited partner if immediately after the partner acquires that interest, (1) limited partners own a substantial, continuing interest in that specific class of partnership interest, and (2) the individual's rights and obligations with respect to the specific class of interest are identical to the rights and obligations of the specific class of interest held by the limited partners (Prop. Reg. 1.1402(a)-2(h)(4)).

An individual who is a service partner in a service partnership may not be a limited partner (Prop. Reg. 1.1402(a)-2(h)(5)). A partnership is a service partnership if substantially all the activities of the partnership involve services in the fields of health, law, engineering, architecture, accounting, actuarial science, or consulting (Prop. Reg. 1.1402-2(h)(5)). A partner is not considered a service partner if that partner only provides a de minimus amount of services to or on behalf of the partnership. Presumably, the de minimus exception was included to deal with retiring partners who continue to receive payments for goodwill and perform some services for the partnership in order to insure a continuation in client service. Unfortunately, there is no guidance on what level of service qualifies as de minimus (Koski, 2005).

The following example illustrates how the 1997 proposed regulations apply to LLCs (Prop. Reg. 1.1402(a)2(i)). Ann, Betty, and Carla form an LLC that elects to be classified as a partnership. LLC is not a service partnership. LLC allocates all items of income, deduction and credit to Ann, Betty, and Carla in proportion to their ownership interests. Ann and Carla each contribute \$1X for one LLC unit, while Betty contributes $\$ 2 X$ for two LLC units. Each LLC unit entitles the owner to 25 percent of LLC's tax items. Ann does not perform services for LLC. Betty receives a guaranteed payment of $\$ 6 \mathrm{X}$ for 600 hours of services rendered to LLC. Carla receives a guaranteed payment of $\$ 10 \mathrm{X}$ for 1,000 hours of services rendered to LLC. Carla is elected LLC's manager, and under state law has the authority to contract on behalf of LLC. 
Ann is not personally liable for the debts of or claims against LLC, does not have authority to contract for LLC, and does not participate in LLC's trade or business for more than 500 hours. Therefore, Ann's distributive share of LLC's income is not NEFSE (Prop. Reg. 1.1402(a)-2(i)).

Betty is not treated as a limited partner under Prop. Reg. 1.1402(a)-2(h)(2) because she participates in the partnership's trade or business for more than 500 hours. She is not treated as a limited partner under Prop. Reg. 1.1402(a)-2(h)(3) because she does not hold more than one class of interest. However, Betty is treated as a limited partner under Prop. Reg. 1.1402(a)-2(h)(4) because the only reason she doesn't qualify as a limited partner under Prop. Reg. 1.1402(a)-2(h)(2) is that she participated in LLC's trade or business for more than 500 hours, and Ann is a limited partner who owns a substantial interest in the partnership with rights identical to Betty's. Therefore, Betty's share of LLC's income is not NEFSE (Prop. Reg. 1.1402(a)-2(i)). The guaranteed payment received by Betty for services rendered to LLC is NEFSE (Prop. Reg. 1.1402(a)-2(g)). Because Betty has no personal liability for the debts of LLC and does not have the authority to contract on behalf of LLC, she was able to participate in LLC's business and still avoid SE tax her share of LLC's earnings.

Carla is not treated as a limited partner under Prop. Reg. 1.1402(a)-2(h)(2) because she has the authority to enter into a binding contract on behalf of LLC, and participates in LLC's trade or business for more than 500 hours. She is not treated as a limited partner under Prop. Reg. 1.1402(a)-2(h)(3) because she does not hold more than one class of interest. In addition, Carla is not treated as a limited partner under Prop. Reg. 1.1402(a)-2(h)(4) because she has the authority to contract on behalf of the partnership. Therefore, Carla is treated as a general partner with respect to her interest in LLC and both her distributive share of LLC's income and the guaranteed payment she received are NEFSE (Prop. Reg. 1.1402(a)-2(i)).

\section{AUTHORITY OF THE 1997 PROPOSED REGULATIONS}

Several senators sent letters to the IRS Commissioner condemning the 1997 proposed regulations. The senators claimed that the proposed regulations violated the requirement that the IRS publish a flexibility analysis whenever proposed regulations require that small businesses collect information (See 5 USC §601-605). They also expressed concern that the proposed regulations, especially the material participation test, would result in a significant tax increase to small businesses. As a result of this criticism, Congress issued a moratorium prohibiting the Treasury from making the regulations final prior to July 1, 1998 (Taxpayer Relief Act of 1997). According to the Committee Reports on this moratorium, Congress, not the IRS, should determine the tax law governing self-employment income (Conf. Com. Rep. No. 105-220).

Although the Congressional moratorium on finalizing the 1997 proposed regulations has long elapsed, they have not been finalized. Neither Congress nor the Treasury has acted on this issue. The Treasury has not withdrawn the 1997 proposed regulations or issued any other definitive guidance.

A proposed regulation is only a proposal until finalized, and are generally given little weight by courts. However, proposed regulations are considered "substantial authority" for purposes of the substantial underpayment penalty (Internal Revenue Code $\S 6662$ ). In addition, courts have on occasion sustained taxpayer positions based on proposed regulations. The tax court, for example, has held that if a taxpayer relies on a proposed regulation the IRS cannot impose a different final regulation detrimental to a taxpayer who acted in reliance on the "most reasonable interpretation" of the issue available to the taxpayer at the time his return was filed (Elkins).

In summary, the continuing silence on this issue creates uncertainty as to how to treat LLCs for SE tax purposes. Although the 1997 proposed regulations were never finalized, they are the most definitive guidance available and represent the current IRS position on the issue. Although uncertainty still surrounds the application of SE tax to LLCs, the 1997 proposed regulations provide taxpayers with opportunities to reduce SE taxes by properly structuring and operating LLCs (Koski, 2005). 


\section{PROPOSALS TO AMEND SE TAX}

In 1999 the American Bar Association Section of Taxation (ABA) recommended that Congress provide a legislative solution to the problem of applying SE tax to LLCs by amending section 1402(a)(13) (ABA Proposal). The ABA worked closely with the Tax Division of the American Institute of Certified Pubic Accountants (AICPA) in developing the recommendations. The ABA noted that uncertainty in how SE tax applies to LLCs is a significant issue and that the lack of guidance creates confusion, uncertainty, and noncompliance.

The ABA recommends that Congress amend section 1402(a)(13) to provide that income attributable to capital is excluded from NEFSE regardless of whether the partner is a general partner, limited partner, LLC member, or member of any other entity classified as a partnership. NEFSE would include all partnership income (regardless of the type of entity) except that attributable to a return on capital. The theory behind this proposal is sound; a return on capital should not be considered SE income. Determining return on capital, however, is problematic.

The ABA recommends adopting two safe-harbors for determining return on capital - an interest based safeharbor and a reasonable compensation safe-harbor. The interest based safe-harbor would allow a partner to treat a reasonable rate of return on unreturned capital as return on capital. The ABA suggests a rate equal to 150 percent of the applicable federal rate, or a higher rate established by regulations. The ABA also suggests that a partner be able to use his or her capital account balance as unreturned capital.

The reasonable compensation safe-harbor would treat an amount in excess of what would be considered reasonable compensation for services rendered as return on capital. This safe-harbor would create issues that parallel the "unreasonably low" compensation issue that arises with S corporations. The IRS has recharacterized S corporation distributions as salary subject to employment taxes in cases where the corporation attempts to eliminate or minimize employment taxes by paying no or unreasonably low compensation to shareholder/employees while making tax-free distributions to them. The determination of reasonable compensation is a factual inquiry determined on a case by case basis. There is a developing line of cases discussing what constitutes reasonable compensation (see Raktke, Spicer Accounting, Inc., Joseph M. Grey Public Accountant, P.C., Nu-Look Design, Inc., Haffner's Service Stations, Inc., Exacto Spring Corp., and Metro Leasing and Development Corporation).

The ABA recommends granting the Treasury the authority necessary to carry out the new SE provisions, and delineates several areas where regulatory guidance would be needed. Regulations issued under this suggested legislation would be extensive because of the many unresolved issues surrounding this proposal.

The ABA believes that a legislative solution to the problem is the best alternative, but goes on to state that if a legislative solution is not forthcoming or will be delayed an extended period of time, the best immediately available approach is finalizing the 1997 proposed regulations, or at least promulgating temporary regulations. In an earlier section of the proposal, the ABA acknowledges that as a result of the Congressional moratorium that followed the 1997 proposed regulations, the Treasury is unlikely to issue new regulations without guidance from Congress. The ABA proposal was made in 1997 and no further guidance has been issued by either Congress or the Treasury.

\section{JCT REPORT}

On January 27, 2005 the Joint Committee on Taxation (JCT) issued a report that recommends, among other things, a complete revision of the SE tax as it applies to partnerships and LLCs (JCT Report). The JCT report proposes that all individuals treated as partners be subject to SE tax on their share of partnership earnings. Similar to the ABA, the JCT recommends that no distinction be made between types of partners. The other recommendations of the JCT, however, are significantly different than the ABA's.

The current law exclusion from NEFSE of certain types of income (certain rental income, dividends, interest, certain gains, and certain other passive-type items) would continue to apply to all partnerships except service partnerships. A partner in a service partnership would be subject to SE tax on their entire share of partnership income, including items excluded from NEFSE under current law. A service partnership would be defined as a partnership 
substantially all of whose activities involve the performance of service in the fields of health, law, engineering, architecture, accounting, actuarial science, performing arts, or consulting. Eliminating service partnerships from the current law exclusion from SE tax for passive-type income has been criticized. Levy (2005) argues that subjecting the passive-type income of service partnerships to SE tax goes beyond the intent of SE tax, which is to tax labor income. Protests from small business can be expected if service partnerships are subject to tax on passive-type income (Levy, 2005).

The JCT proposal provides an exception for any partner (regardless of whether the partner is a general partner, limited partner, or LLC member) who does not materially participate in the partnership's trade or business. In the case of a partner who does not materially participate in the partnership's trade or business, only the partner's reasonable compensation from the partnership is NEFSE. The material participation tests set forth in the section 469 regulations (the passive loss rules) would apply for purposes of determining whether a partner materially participates in the partnership's trade or business for SE tax purposes.

The JCT acknowledged that because the determination of reasonable compensation is a factual determination it could be questioned whether it has the predictability desired of a legislative proposal, but stated that because reasonable compensation is used to determine NEFSE only for partners who do not materially participate in the partnership's business, the situations where the reasonable compensation standard applies is limited. The JCT dismissed suggestions that the reasonable compensation test be applied to all limited partners and LLC members because they felt that administrative concerns would make the approach less attractive then the mechanical approach taken.

The JCT proposal would change SE tax in several ways. Some general partners would pay less SE tax under the JCT proposal. A general partner is currently subject to SE tax on his or her entire share of partnership income. Under the JCT proposal a general partner who doesn't materially participate in the partnership's trade or business would only be subject to SE tax on his or her reasonable compensation. A limited partner is currently not subject to SE tax on his or her share of partnership income. Under the JCT proposal a limited partner who materially participates in the partnership's trade or business would be subject to SE Tax on his or her entire share of partnership earnings (other than the exception for interest, dividends, and other types of passive-type income available to nonservice partnerships) (Levy, 2005).

The JCT proposal attempts to base SE tax on labor income and improve tax neutrality by reducing the importance of SE tax in choice of business entity decisions. The JCT recommends that this same rule be applied to S corporations. The JCT declined to endorse the return on capital approach of the ABA. While the return on capital approach may be theoretically sound, the JCT concluded that it "raises administrability concerns, as rates of return can vary significantly among different types of businesses, at different times in the life of a business activity, and with different management of the business, among other factors" (JCT Report).

\section{DISCUSSION}

Most commentators agree that the rules regarding how SE taxes apply to LLCs need to be clarified, and that the new standards should apply to all entities classified as a partnership for tax purposes (Levy, 2005; Fritz, 1998). Applying SE tax to all entities classified as a partnership is now appropriate. There was a rational basis for distinguishing between general and limited partners in 1977. State laws have changed dramatically since then. Most state partnership laws now permit limited partners to participate in the management of the partnership without jeopardizing limited liability. More significantly LLCs have become an important form of business entity. LLC owners are partners for tax purpose, but are neither general nor limited partners. Consistent rules are needed to determining how SE tax applies to all entities classified as partnerships, including LLCs.

The more difficult issue is developing an appropriate set of uniform rules. As noted by Dilley (2000) the complications in applying SE tax to partnerships are required because of the underlying imperative that Social Security benefit eligibility be tied to earnings. There is no employer-employee relationship inherent in partnerships and the absence of an outward marker (wages paid on account of services rendered) makes it "difficult, if not 
impossible, to distinguish with absolute certainty between wages and income unconnected with services, such as income from capital of various types" (Dilley, 2005).

The return of capital approach suggested by the ABA and the approach suggested by the JCT are both reasonable approaches to a complex problem. Both proposals, however, have inherent problems that would need to be addressed if the proposals were enacted. Although a return on capital approach is theoretically sound, defining a reasonable rate of return raises several administrative concerns (JCT Report).

Whatever approach is taken, guidance on how SE taxes apply to LLCs is needed. A legislative solution would be appropriate. Until there is a legislation solution to this problem, I agree with the ABA that finalization of the 1997 proposed regulations, or issuance of new temporary regulations, is the next best alternative. Until further guidance is issued, the 1997 proposed regulations are the most authoritative guidance available on when LLC earnings are subject to SE tax, and practitioners should consider using these proposed regulations as a guide for structuring their clients' LLCs in a way that minimizes SE tax (Koski, 2005).

\section{REFERENCES}

1. ABA Tax Section Suggests Legislative Fix for LLC Self-Employment Tax, 1999 Tax Notes Today 133-23 (July 13, 1999).

2. $\quad$ Conf. Com. Rep. No. 105-220, Taxpayer Relief Act of 1997, (Pub. L No. 105-34).

3. Dilley, Patricia E., Breaking the Glass Slipper - Reflections on the Self-Employment Tax, 54 Tax Law. 65 (Fall 2000).

4. $\quad$ Elkins v. Commissioner, 81 T.C. 669, Dec. 40,514 (1983).

5. $\quad$ Exacto Spring Corp. V. Commissioner, 196 F.3d 833 ( $7^{\text {th }}$ Cir. 1999).

6. Fritz, Thomas R., Flowthrough Entities and the Self-Employment Tax: Is It Time for a Uniform Standard? 17 Va. Tax Rev. 811 (1998).

7. Haffner's Service Stations, Inc. v. Commissioner, 326 F.3d 1 ( $\left({ }^{\text {st }}\right.$ Cir. 2003).

8. $\quad$ Internal Revenue Code $\S 1401,26$ U.S.C. $\$ 1401$.

9. $\quad$ Internal Revenue Code $\S 1402,26$ U.S.C. $\$ 1402$

10. Joseph M. Grey Public Accountant, P.C. v. U.S., 119 T.C. 121 (2002), aff'd, 93 Fed. Appx. 473 (3 ${ }^{\text {rd }}$ Cir. 2004).

11. Koski, Timothy R., Self-Employment Tax and Limited Liability Companies: When are LLC Earnings Subject to Self-Employment Tax? Taxes - The Tax Magazine, (September 2005).

12. Levy, Thomas R., The Role of Limited Liability in Determining Self-Employment Income Tax: The Continuing Conundrum of the LLC member. 2005 Tax Notes Today, 114-38 (June 15, 2005.

13. Metro Leasing and Development Corporation v. Commissioner, 376 F.3d 1015 (9 $9^{\text {th }}$ Cir. 2004).

14. Nu-Look Design, Inc. v. Commissioner, 356 F.2d 290 (3rd Cir. 2004).

15. Prop. Reg. § 1.1402(a)-2, 62 Fed. Reg. 1702 (January 13, 1997).

16. Prop Reg. § 1.1402(a)-18(c)(3), 59 Fed Reg. 67253 (December 29, 1994).

17. Radtke v. U.S., 895 F.2d $1196\left(7^{\text {th }}\right.$ Cir. 1990).

18. Spicer Accounting, Inc. v. U.S., 918 F.2d 90 (9 $9^{\text {th }}$ Cir. 1990).

19. Staff of the Joint Committee on Taxation, $108^{\text {th }}$ Cong., Options to Improve Tax Compliance and Return Tax Expenditures, (Comm. Print 2005).

20. Social Security Amendments of 1977, (Pub. L. No. 95-216).

21. Taxpayer Relief Act of 1997, Pub. L. No. 105-34, § 935. 


\section{NOTES}

